\title{
DETERMINING RELIABILITY PARAMETERS FOR A CLOSED- CYCLE SMALL COMBINED HEAT AND POWER PLANT
}

\author{
Vladimir S. Vysokomorny ${ }^{1}$, Olga V. Vysokomornaya ${ }^{1, \text { a }}$, Maxim V. Piskunov ${ }^{1}$ \\ ${ }^{1}$ National Research Tomsk Polytechnic University, 634050 Tomsk, Russia
}

\begin{abstract}
The paper provides numerical values of the reliability parameters for independent power sources within the ambient temperature and output power range corresponding to the operation under the climatic conditions of Eastern Siberia and the Far East of the Russian Federation. We have determined the optimal values of the parameters necessary for the reliable operation of small CHP plants (combined heat and power plants) providing electricity for isolated facilities.
\end{abstract}

\section{Introduction}

Depletion of hydrocarbon reserves and increase in the cost of organic fuel encourage the efficiency of power engineering technologies to improve and promote the optimization of power transmission to consumers [1-3].

Extractive companies make extensive use of independent power sources (particularly, small CHP plants). For instance, hydrocarbons are traditionally delivered from their production sites to consumers by main pipelines, which requires electric energy costs for pump and compressor stations. In the Russian Federation, a significant share of such main lines is located on the territories of Eastern Siberia and the Far East. The energy infrastructure on these territories is underdeveloped, and independent power sources are often the optimal way to supply energy to remote destinations of crude hydrocarbon transportation. Despite their high-tech energy equipment, the companies that make use of such power facilities suffer from failures of independent power sources, which has a negative effect on the operation of the whole main pipeline.

From the above it follows that the reliability of independent power sources is among the key factors in the promotion of energy security for any production (especially those geographically remote from the centralized energy system), and individual reliability parameters of independent power sources are worth a detailed study.

Information on physical regularities in the technological process of an independent power source and on changes in its operation parameters when it is exposed to external and internal factors makes it possible to evaluate the reliability of a power facility in general and its separate elements in particular.

The aim of this work is to analyze the effect of internal and external factors on the reliability indicators of a small CHP plant operating on an organic working substance and used for the power supply of the gas transmission system of Eastern Siberia and the Far East of the Russian Federation.

${ }^{a}$ Corresponding author: vysokomornaja@tpu.ru

This is an Open Access article distributed under the terms of the Creative Commons Attribution License 4.0, which permits unrestricted use, distribution, and reproduction in any medium, provided the original work is properly cited. Article available at nttp://wwW.epl-conferences.org or nttp://dx.dol.org/10.1051/ep/cont/20161100108d 


\section{Problem statement and solution methods}

The object of this research is a small closed-cycle CHP plant using an organic fluid, dichlorobenzene, as a working substance [1]. According to the analysis [3], one of the most common causes of failure in such sources of power supply when used in the climates of Eastern Siberia and the Far East of Russia is the temperature of the working fluid at the condenser outlet exceeding the limit values [1].

To determine the reliability criteria for the operation of a small CHP plant condenser, we used a heat and mass transfer model [1]. The cycle fluid in the vapor state at a saturation temperature of $T_{\mathrm{S}}$ is fed to the condenser pipes. Due to the heat exchange with the environment (ambient air) through the pipe walls, heat is removed from the vapors of the working substance flowing within the condenser at a speed of $V_{1}$. With the phase changing, a condensate film is formed on the pipe inner surface. As the vapor moves through the pipes, the condensate film thickness $\delta$ goes up, whereas the vapor fraction in the liquid-vapor mixture $\varphi_{\mathrm{v}}$ goes down. When the phase change is over, further heat removal from the cycle fluid is accompanied by a decrease in its temperature [1].

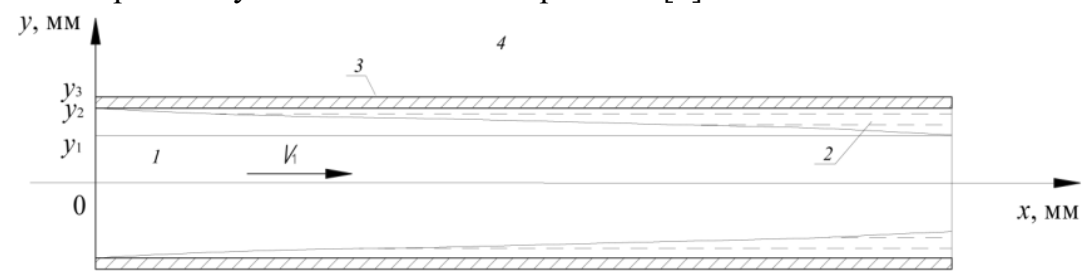

Figure 1. Schematic representation of the solution region for the problem: vapors of the cycle fluid (1); condensate (2); condenser pipe wall (3); ambient air (4).

Transient differential equations describe the cycle fluid condensation in the pipes of a condenser unit (Fig. 1) and correspond to the physical statement of the problem formulated. They look as follows in the Cartesian coordinates [1].

Thermal conduction equation for cycle fluid in the condensation zone $\left(T_{1}=T_{\mathrm{s}}, 0<x<x_{1}, 0<y<y_{1}\right)$ :

$$
\frac{\partial T_{1}}{\partial t}+V_{1} \frac{\partial T_{1}}{\partial x}=a_{1}\left(\frac{\partial^{2} T_{1}}{\partial x^{2}}+\frac{\partial^{2} T_{1}}{\partial y^{2}}\right)+\frac{W_{\mathrm{c}} \cdot Q_{\mathrm{c}}}{c_{1} \cdot \rho_{1}} .
$$

Thermal conduction equation for cycle fluid out of the condensation zone $\left(T_{1}<T_{\mathrm{s}}, 0<x<x_{1}\right.$, $\left.y_{1}<y<y_{2}\right)$ :

$$
\frac{\partial T_{2}}{\partial t}+V_{2} \frac{\partial T_{2}}{\partial x}=a_{2}\left(\frac{\partial^{2} T_{2}}{\partial x^{2}}+\frac{\partial^{2} T_{2}}{\partial y^{2}}\right)
$$

Thermal conduction equation for the wall $\left(0<x<x, y_{2}<y<y_{3}\right)$ :

$$
\frac{\partial T_{3}}{\partial t}=a_{3}\left(\frac{\partial^{2} T_{3}}{\partial x^{2}}+\frac{\partial^{2} T_{3}}{\partial y^{2}}\right)
$$

Working substance flow equation $\left(T_{1}<T_{\mathrm{s}}, 0<x<x_{1}, 0<y<y_{1}\right)$ :

$$
\frac{\partial V_{1}}{\partial t}+V_{1} \frac{\partial V_{1}}{\partial x}=-\frac{1}{\rho_{1}} \frac{\partial P_{1}}{\partial x}
$$

Initial conditions: $t=0 ; T_{1}=T_{0}, \varphi_{\mathrm{v}}=1$.

Boundary conditions:

1) At the boundaries of liquid-vapor mixture and the condensate film

$$
\text { with } 0<x<x_{1}, y=y_{1} \quad \frac{\partial T_{1}}{\partial x}=\frac{\lambda_{2}}{\lambda_{1}} \frac{\partial T_{2}}{\partial x}, T_{1}=T_{2} \text {; }
$$

2) At the boundary of the condensate film and pipe inner surface

with $0<x<x_{1}, y=y_{2} \alpha_{1-2}\left(T_{2}-T_{3}\right)=\lambda_{3}\left(\frac{\partial T_{3}}{\partial y}\right)$, 
$\alpha_{1-2}=0.638\left[\frac{\lambda_{3}^{2} \rho_{2}\left(\rho_{2}-\rho_{1}\right) g Q_{\mathrm{c}}}{\eta_{2} D_{\text {in }}\left(T_{\mathrm{s}}-T_{3}\right)}\right]$;

3) At the boundary of the pipe outer surface and the air

with $0<x<x_{1}, y=y_{3} \frac{\partial T_{3}}{\partial x}=\frac{\lambda_{4}}{\lambda_{3}} \frac{\partial T_{4}}{\partial x}, T_{3}=T_{4}$;

4) On the symmetry axis of the pipeline

with $0<x<x_{1}, y=0 \quad \frac{\partial^{2} T_{1}}{\partial x^{2}}=0$.

In the system of equations (1) - (9), we use the following notations: $T$ denotes temperature (K); $T_{\mathrm{S}}$ is the working substance saturation temperature $(\mathrm{K}) ; x, y$ denote the Cartesian coordinates $(\mathrm{m}) ; t$ is time (s); $V$ is the working substance flow rate $(\mathrm{m} / \mathrm{s}) ; a$ is the coefficient of heat diffusivity $\left(\mathrm{m}^{2} / \mathrm{s}\right) ; W_{\mathrm{c}}$ is the volumetric flow rate of the working substance $\left(\mathrm{m}^{3} / \mathrm{s}\right) ; Q_{\mathrm{c}}$ is the latent energy of phase change $(\mathrm{J} / \mathrm{kg}) ; c$ is mass heat capacity $(\mathrm{J} / \mathrm{kg} \cdot \mathrm{K}) ; \rho$ is density $\left(\mathrm{kg} / \mathrm{m}^{3}\right) ; P$ is the pressure of the working substance $\left(\mathrm{N} / \mathrm{m}^{2}\right) ; \varphi_{\mathrm{v}}$ is the vapor fraction in the two-phase flow; $\lambda$ is the coefficient of heat conductivity $(\mathrm{W} /(\mathrm{m} \cdot \mathrm{K})) ; T_{0}$ is the temperature of the working substance at the initial instant $(\mathrm{K}) ; g$ is gravity acceleration $\left(\mathrm{m} / \mathrm{s}^{2}\right) ; \eta$ is the coefficient of dynamic viscosity $\left(\mathrm{m}^{2} / \mathrm{s}\right) ; D_{\text {in }}$ is the inside diameter of the pipeline $(\mathrm{m})$; indexes $1,2,3$, and 4 denote the liquid-vapor mixture, the liquid phase of the working substance, the material of the condenser pipes, and air.

The working substance vapor density was calculated using the following formula:

$\rho_{1}=\frac{P_{1} \cdot M}{R_{\mathrm{t}} \cdot T_{1}}$,

where $M$ denotes the molar weight of working substance $(\mathrm{kg} / \mathrm{kmol})$ and $R_{\mathrm{t}}$ is the gas constant $(\mathrm{J} /(\mathrm{mol} \cdot \mathrm{K}))$.

The condensation flow rate was derived from the expression:

$W_{\mathrm{c}}=\frac{\beta}{1-k_{\beta} \beta} \frac{\varphi_{\mathrm{v}}\left(P_{1}^{\mathrm{n}}-P_{1}\right)}{\sqrt{2 \pi R_{\mathrm{t}} T_{1} / M}}$,

where $\beta$ is the nondimensional coefficient of condensation; $\mathrm{k}_{\beta}$ is the nondimensional coefficient equal to $0.4 ; P^{\mathrm{n}}$ is the saturated vapor pressure of the working substance $\left(\mathrm{N} / \mathrm{m}^{2}\right)$.

\section{Results and Discussion}

The data on the operation modes of the closed-cycle CHP plant under study show malfunctions of the independent power sources, when the outlet temperature of the working fluid in the condenser exceeds $55{ }^{\circ} \mathrm{C}$ [3]. Since these small power plants operate under various climatic conditions, it is advisable to assess failure risks at $T_{\text {output }}>55^{\circ} \mathrm{C}$ depending on the ambient temperature and the facility power.

The model used allowed us to calculate the output temperature $T_{\text {output }}$ of the working fluid exposed to various external and internal factors (Table 1).

The computational results obtained have been used to determine the mean time between failures of the independent power sources under study when operating under the climatic conditions of Eastern Siberia and the Far East of Russia. The mean time between failures (when considering a condenserrelated failure situation) is a time interval when the output temperature of the working fluid $T_{\text {output }}<$ $T_{\text {output }}^{\text {кp }}=328 \mathrm{~K}$ is recorded.

The condenser performance reliability for the small power plant under study is calculated for the climatic conditions of the Amur Region of the Russian Federation. The data shown in Table 1 make it possible to conclude that when an independent source of a power facility operates at nominal power $\left(P=2000 \mathrm{~W}, T_{\text {input }}=426 \mathrm{~K}\right)$, the output temperature of the working substance may exceed the critical value at the ambient temperature of approx. $T_{\text {out }}=293 \mathrm{~K}$. According to long-term climatic observations in the city of Blagoveschensk, the mean annual duration of the ambient temperature of 
$293 \mathrm{~K}$ or higher amounts to 1157 hours. Thus, the mean time between failures at $P=2000 \mathrm{~W}$ will make $T_{0}=7603$ hours under the climatic conditions of the Amur Region, Russian Federation.

Table 1. Output temperatures of the working fluid at different values of the facility power and ambient temperature.

\begin{tabular}{|c|c|c|c|c|c|c|c|c|}
\hline $\begin{array}{c}T_{\text {out, }} \\
\mathrm{K}\end{array}$ & $\begin{array}{c}T_{\text {input }}, \\
\mathrm{K}\end{array}$ & $\begin{array}{c}T_{\text {output }}, \\
\mathrm{K}\end{array}$ & $\begin{array}{c}T_{\text {input }}, \\
\mathrm{K}\end{array}$ & $\begin{array}{c}T_{\text {output }}, \\
\mathrm{K}\end{array}$ & $\begin{array}{c}T_{\text {input }}, \\
\mathrm{K}\end{array}$ & $\begin{array}{c}T_{\text {output }}, \\
\mathrm{K}\end{array}$ & $\begin{array}{c}T_{\text {input }}, \\
\mathrm{K}\end{array}$ & $\begin{array}{c}T_{\text {output }}, \\
\mathrm{K}\end{array}$ \\
\hline 253 & \multirow{7}{*}{$\begin{array}{c}447 \\
(P=4000 \\
W)\end{array}$} & 334.73 & \multirow{7}{*}{$\begin{array}{c}438 \\
(P=3000 \\
W)\end{array}$} & 318.73 & \multirow{7}{*}{$\begin{array}{c}426 \\
(P=2000 \\
W)\end{array}$} & 311.35 & \multirow{7}{*}{$\begin{array}{c}403 \\
(P=1000 \\
W)\end{array}$} & 306.08 \\
\hline 263 & & 338.67 & & 322.43 & & 314.24 & & 308.75 \\
\hline 273 & & 343.4 & & 326.41 & & 318.02 & & 312.43 \\
\hline 283 & & 348.91 & & 330.67 & & 322.66 & & 317.09 \\
\hline 293 & & 355.19 & & 335.21 & & 328.19 & & 322.77 \\
\hline 303 & & 362.26 & & 340.04 & & 334.61 & & 329.44 \\
\hline 313 & & 370.11 & & 345.14 & & 341.89 & & 337.11 \\
\hline
\end{tabular}

A power facility with $P=4000 \mathrm{~W}$ faces maximum failure risks in the operation of a small power plant within the ambient temperature range under consideration due to marginal temperature of the working substance in the condenser. See Table 2 for the mean time between failures calculated for the climatic conditions in other administrative subjects of Eastern Siberia and the Far East of Russia where the main pipelines of the RF gas transmission system are located.

Table 2. Mean time between failures under climatic conditions of Eastern Siberia and the Far East of the RF.

\begin{tabular}{|c|c|c|c|c|c|c|}
\hline Power $(\mathrm{W})$ & $\begin{array}{c}\text { Blagoseschensk } \\
T_{0}(\mathrm{~h})\end{array}$ & $\begin{array}{c}\text { Bochugany } \\
T_{0}(\mathrm{~h})\end{array}$ & $\begin{array}{c}\text { Vladivostok } \\
T_{0}(\mathrm{~h})\end{array}$ & $\begin{array}{c}\text { Kovykta } \\
T_{0}(\mathrm{~h})\end{array}$ & $\begin{array}{c}\text { Okha } \\
T_{0}(\mathrm{~h})\end{array}$ & $\begin{array}{c}\text { Petropavlovsk- } \\
\text { Kamchatsky } T_{0} \\
(\mathrm{~h})\end{array}$ \\
\hline$P=3000 \mathrm{~W}$ & 4533 & 5219 & 4037 & 5516 & 4921 & 5448 \\
\hline$P=2000 \mathrm{~W}$ & 7603 & 8129 & 8226 & 8198 & 7352 & 7932 \\
\hline$P=1000 \mathrm{~W}$ & 8628 & 8699 & 8546 & 8698 & 8234 & 8136 \\
\hline
\end{tabular}

The data shown in Table 2 allow us to forecast failures caused by marginal temperature at the condenser output of a small CHP plant operating on the territory of Eastern Siberia and the Far East of Russia. The results obtained can be used to adjust the operation modes of the small power plants under study.

\section{Conclusions}

The numerical research findings were used to determine the reliability of independent power sources operating in the regions of various climatic conditions. We also defined the parameters necessary for fail-safe operation of the power facilities under study.

The climatic conditions considered as an example to calculate the mean time between failures are characterized by long periods of low ambient temperature. If similar independent power facilities are used in the regions of the central part of the Russian Federation with milder climate and longer periods of positive atmospheric temperature, the performance reliability of independent power facilities will improve significantly. 


\section{Acknowledgments}

The research was financially supported by the grant of the President of the Russian Federation (MD2806.2015.8).

\section{References}

1. M.V. Piskunov, I.S. Voytkov, O.V. Vysokomornaya, V.S. Vysokomorny, EPJ Web of Conf. 82 (2015).

2. A.E. Kontorovich, M.I. Epov, L.V. Russian Geology and Geophysics. 5-6, 55 (2014).

3. EPS Operation and Maintenance Manual (powered by CCVT) (ORMAT SYSTEMS LTD, Part 2, 2006). 